\title{
Effect of hydrostatic pressure on structural and electronic properties of TGS crystals (first-principle calculations)
}

\author{
B.Andriyevsky, W.Ciepluch-Trojanek, A.Patryn \\ Koszalin University of Technologies, Faculty of electronics and computer sciences, \\ 2 Sniadeckich Str., 75-453 Koszalin, Poland
}

Received September 4, 2006

First principle calculations of the effect of hydrostatic pressure on the structural and electronic parameters of TGS crystals have been carried out within the framework of density functional theory using the CASTEP code. The volume dependence of total electronic energy $E(V)$ of the crystal unit cell satisfies the third-order Birch-Murnaghan isothermal equation of state. For the pressure range of $-5 \ldots 5 \mathrm{GPa}$, the bulk modulus was found to be equal to $K=45 \pm 5 \mathrm{GPa}$. The relative pressure changes of the unit cell parameters were found to be linear in the range of $-5 \ldots 5 \mathrm{GPa}$. Crossing of the pressure dependencies of enthalpy corresponding to the ferroelectric and non-ferroelectric phases at $P=7.7 \mathrm{GPa}$ testifies to the probable pressure induced phase transition in TGS crystal.

Key words: ferroelectrics, structure and electronic parameters, hydrostatic pressure

PACS: $71.15 . \mathrm{Nc}, 77.80 . \mathrm{Bh}, 77.84 . \mathrm{Fa}$

\section{Introduction}

The triglycine sulphate (TGS), $\left(\mathrm{CH}_{2} \mathrm{NH}_{2} \mathrm{COOH}\right)_{3} \cdot \mathrm{H}_{2} \mathrm{SO}_{4}$, is a known ferroelectric crystal [1], which undergoes a phase transition at $49^{\circ} \mathrm{C}$ resulting in two structural changes: (1) continuous reorientation of the $\mathrm{NH}_{3}^{+}$group of the glycine- 1 (G1) about the $a c$ plane at $1 / 4 \mathrm{~b}$ and $3 / 4 \mathrm{~b}$ making it a statistically averaged mirror in the high-temperature paraelectric phase; (2) disordering of the proton that connects the G2 and G3 groups making the two glycine ions indistinguishable in the high-temperature paraelectric phase.

The static pressure is a continuously varying parameter which can be used in systematic studies of the properties of solids as a function of interatomic distances. An interesting phenomenon that may occur at the applied pressure is a sudden change in the arrangement of the atoms, i.e., a structural phase transition. The Gibbs free energies of different possible arrangements of atoms vary under compression, and at some stage it becomes favourable for the material to change the type of atomic arrangement. A phase transition is said to have occurred if the change is discontinuous or continuous but with a change in crystal symmetry. The pressures reached in the experiment can lead to a reduction in the volume by over a factor of 2 , causing enormous changes to the inter-atomic bonding [2]. Generally, at the pressure increase the materials adopt high-symmetry structures of increasing coordination number. However, in some cases the previously unexpected lower-symmetry phases are formed at intermediate pressures [3]. Presumably simple high-symmetry structures are adopted at very high pressures.

It is known that the transition temperature of TGS increases for the applied pressure up to $1.5 \mathrm{GPa}[4,5]$. This is caused by a decrease of the distance between the dipole moments of $\mathrm{NH}_{3}^{+}$ groups of G1 with the application of pressure causing an increase of the dipolar interaction [6]. However, at the pressure increase beyond $2.5 \mathrm{GPa}$ the spontaneous polarization $P_{s}$ drops to zero, which is caused by deterioration of the sample due to the penetration of the pressure-transferring medium into the crystal studied [4]. Probably, the authors of the paper [5], did not take the latter conclusion into account. They interpreted the mentioned experimental fact as the phase transition 
causing a pressure stabilized non-ferroelectric state different from the paraelectric state [5]. The authors of the paper [6] have suggested that this non-ferroelectric state takes place because the unit cell dipole moment goes to zero as a result of the glycine-1 group becoming planar and lying in the $Y$-plane of the crystal. Therefore, the main aim of the present paper is to verify this supposition. It is interesting to carry out the first-principle study of the effect of hydrostatic pressure on the structural stability of TGS crystal for the structural space groups of symmetry $P 2_{1}$ and $P 2_{1} / m$ corresponding to the ferroelectric and non-ferroelectric (paraelectric) phases, respectively. Recently, the first-principle study of the mechanically free TGS crystal in the ferroelectric phase has been carried out (see [7]).

\section{Methods of calculations}

Calculations of the electronic energy structure of TGS crystal have been performed within the framework of the density function theory (DFT) using the pseudopotentials-plane-wave-basisset CASTEP code [8]. The calculations were performed within the framework of the generalized gradient approximation (GGA) for the exchange and correlation effects with the ultrasoft pseudopotentials [7]. These pseudopotentials require a quite low energy cutoff and guarantee good transferability, that is, the same potential correctly reproduces the valence electron scattering by the ionic core in different chemical environments. The cutoff energy of $340 \mathrm{eV}$ was used in the plane-wave basis set. Optimization (relaxation) of the atomic positions and the crystal unit cell parameters $(a, b, c$, and $V$ ) was performed for every magnitude of hydrostatic pressure applied to the crystal prior to the calculations of the total electronic energy $E$ and enthalpy $H$.

\section{Results and discussion}

Results of the effect of hydrostatic pressure on the atomic structure parameters of TGS crystal for the space group $P 2_{1}$ (ferroelectric phase) are presented in figures 1 and 2 .

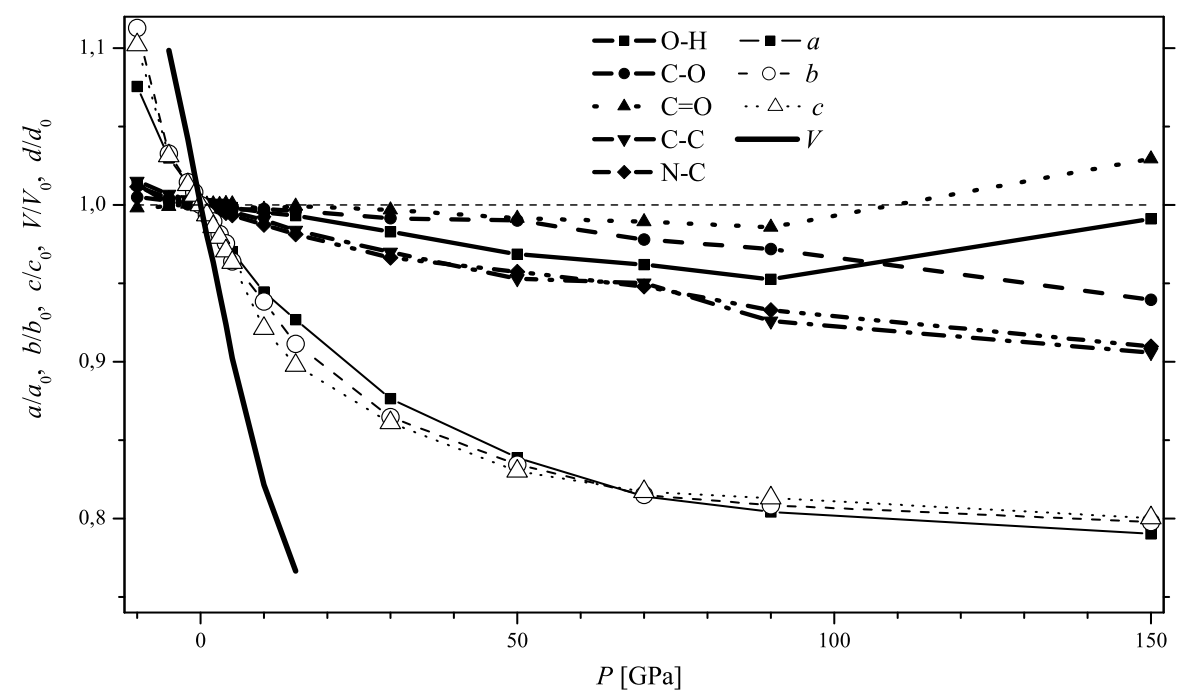

Figure 1. Pressure dependencies of the relative unit cell parameters $a / a_{0}, b / b_{0}, c / c_{0}, V / V_{0}$, and interatomic distances $d / d_{0}$ of the glycine group of TGS crystal.

The relations $a / a_{0}, b / b_{0}$, and $c / c_{0}$ are almost the same for the pressures in the range of $-11 \ldots 150 \mathrm{GPa}$. However a bit greater compressibility takes place for the c-direction (figure 1). Almost equal compressibilities of the crystal for different crystallographic directions are evidently caused by the relatively big part of empty space between separate sulphate and glycine groups of 
TGS crystal. This statement is also in agreement with the result that the substantially smaller changes of interatomic distances are observed for the sulphate and glycine groups regarding the compressibility of the whole crystal unit cell (figure 1). The relative pressure changes of the unit cell parameters are linear in the range of $-5 \ldots 5 \mathrm{GPa}$ but become substantially nonlinear for higher pressure, $P>5 \mathrm{GPa}$ (figure 1). One must take into account this result when, for instance, the quantitative characteristics of the stress-strain effect have to be obtained.

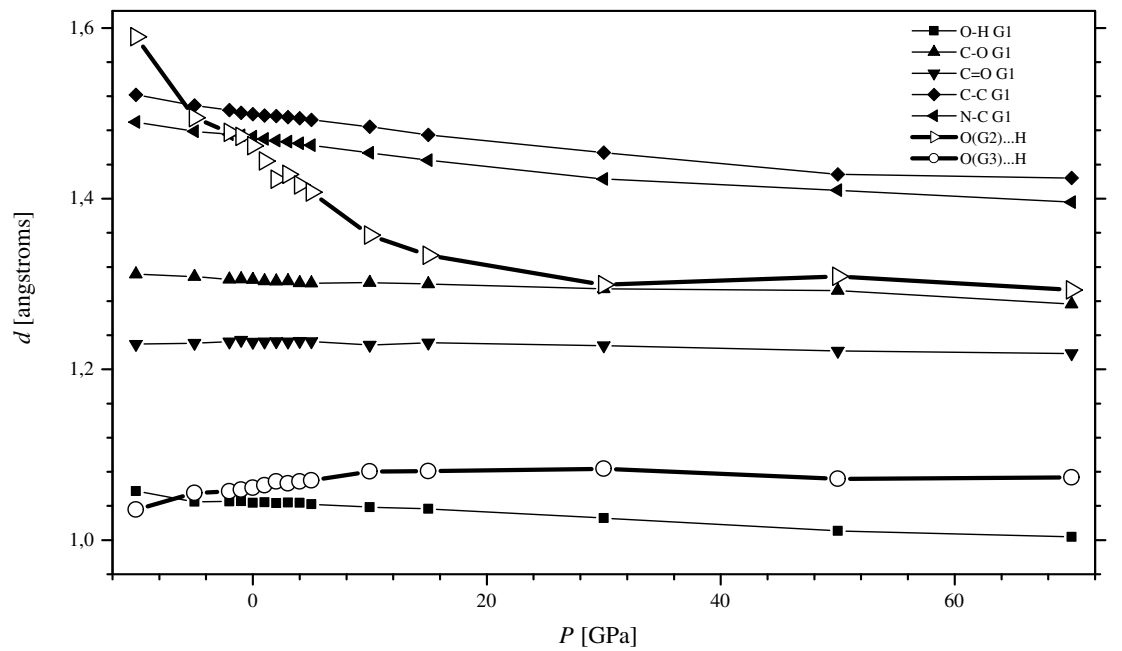

Figure 2. Pressure dependencies of the interatomic distances $d$ of the glycine group G1 and hydrogen bond $\mathrm{O}(\mathrm{G} 2)-\mathrm{H} . . \mathrm{O}(\mathrm{G} 3)$ of TGS crystal.

Relative interatomic distances between different atomic pairs S-O of the sulphate group $d / d_{0}$ are almost the same and are limited by the magnitude of 0.95 for the pressure up to 150 GPa. However, similar statement for the glycine groups is not true, because the relative changes of the distances, $\left(1-d / d_{0}\right)$, for the atomic pairs $\mathrm{C}=\mathrm{O}$ and $\mathrm{C}-\mathrm{O}$ are $2-3$ times smaller than for the $\mathrm{C}-$ $\mathrm{C}$ and $\mathrm{N}-\mathrm{C}$ pairs (figure 1). Mulliken population analysis of electronic structure of the crystal has revealed a pressure induced decrease of the ionicity of structure elements and the increase of the bond covalency of glycine and sulphate groups. Generally this leads to the pressure induced increase of the local electronic symmetry of these groups and thus can favour the pressure induced structural phase transition from the space group $P 2_{1}$ to the higher space group $P 2_{1} / m$ [6].

The unit cell volume dependence of total electronic energy $E(V)$ obtained is satisfactorily approximated by the third-order Birch-Murnaghan isothermal equation of state [9] for the relatively wide range of the volume reduction ratio $V_{0} / V$ :

$$
E(V)=E_{0}+\frac{9 V_{0} K_{0}}{16}\left\{\left[\left(\frac{V_{0}}{V}\right)^{\frac{2}{3}}-1\right]^{3} K_{0}^{\prime}+\left[\left(\frac{V_{0}}{V}\right)^{\frac{2}{3}}-1\right]^{2}\left[6-4\left(\frac{V_{0}}{V}\right)^{\frac{2}{3}}\right]\right\} .
$$

For the pressure range of $-5 \ldots 5 \mathrm{GPa}$ the bulk modulus $K$ and its derivative $K^{\prime}$ were found by fitting procedure to be equal to $K=45.3 \pm 4.8 \mathrm{GPa}$ and $K^{\prime}=3.07 \pm 2.8$. The analogous values for the wider pressure range of $-11 \ldots 150 \mathrm{GPa}$ are equal to $K=43.4 \pm 2.8 \mathrm{GPa}$ and $K^{\prime}=3.14 \pm 0.11$. The magnitudes of $K$ and $K^{\prime}$ calculated for these pressure ranges are close, showing a good applicability of the equation (1) to the case of TGS crystal.

Taking into account the following theoretical dependence on thermodynamical material properties [10],

$$
\alpha=\frac{\gamma C_{V}}{K V}
$$


we have calculated the bulk modulus, $K=50 \mathrm{GPa}$, using the following reference data of the TGS crystal: the heat capacity ratio $\gamma \approx 1$, the specific heat capacity at constant volume $c=1530 \mathrm{~J} /(\mathrm{kg} \cdot \mathrm{K})$, the coefficient of thermal linear expansion $\alpha=0.5 \cdot 10^{-4} \mathrm{~K}^{-1}$, the density $\rho=1660 \mathrm{~kg} / \mathrm{m}^{3}$ [11]. The value of $\gamma$ is typically close to 1 for solids. Due to the general character of the equation (2), the bulk modulus $K$ obtained in this paper from the first principle calculations satisfactorily agrees with the approximate magnitude of $K$ calculated from the equation (2).

The analysis of the results obtained have shown interesting pressure dependencies of the interatomic distances associated with the hydrogen atom located between the glycine- 2 and glycine- 3 groups of the crystal (figure 2). One can presume from these data that this hydrogen atom has a tendency to be located in the middle of the distance between two oxygen atoms of the glycine- 2 and glycine-3 under the increase of hydrostatic pressure. It is also seen in the figure 2 that the bigger interatomic distance $\mathrm{O}(\mathrm{G} 2)-\mathrm{H}$ is characterized by the greatest coefficient of pressure change $\mathrm{d} d / \mathrm{d} P$ in the range of $-5 \ldots 11 \mathrm{GPa}$. This means that for the compressed state, the hydrogen atom becomes an interacting one essentially with both oxygen atoms $\mathrm{O}(\mathrm{G} 2)$ and $\mathrm{O}(\mathrm{G} 3)$ of the glycine-2 and glycine-3 groups. At the same time, these fast pressure changes of the position of hydrogen atom between glycine- 2 and glycine- 3 groups can be interpreted as a continuous part of the pressure induced phase transition $[4,5]$.

For the non-ferroelectric phase (space group $P 2_{1} / m$ ), the enthalpy of the crystal, $H=E+P V$, becomes smaller than that for the ferroelectric phase for the pressure $P>7 \mathrm{GPa}$ (figure 3 ). This permits to suggest a pressure induced phase transition in TGS crystal from the ferroelectric to the non-ferroelectric phase. The analysis of the pressure induced orientation of the $\mathrm{C}-\mathrm{N}$ bond of the glycine-1, associated with the main input into the spontaneous polarization of TGS crystal, has not revealed essential changes of the angle between $\mathrm{C}-\mathrm{N}$ bond and $Y$-axis and corresponding changes of spontaneous polarization, which agrees well with the experimental results of [4]. This means that the pressure induced phase transition from the ferroelectric (space group $P 2_{1}$ ) to the non-ferroelectric phase (space group $P 2_{1} / m$ ) (see [6]) can be of discontinuous type.

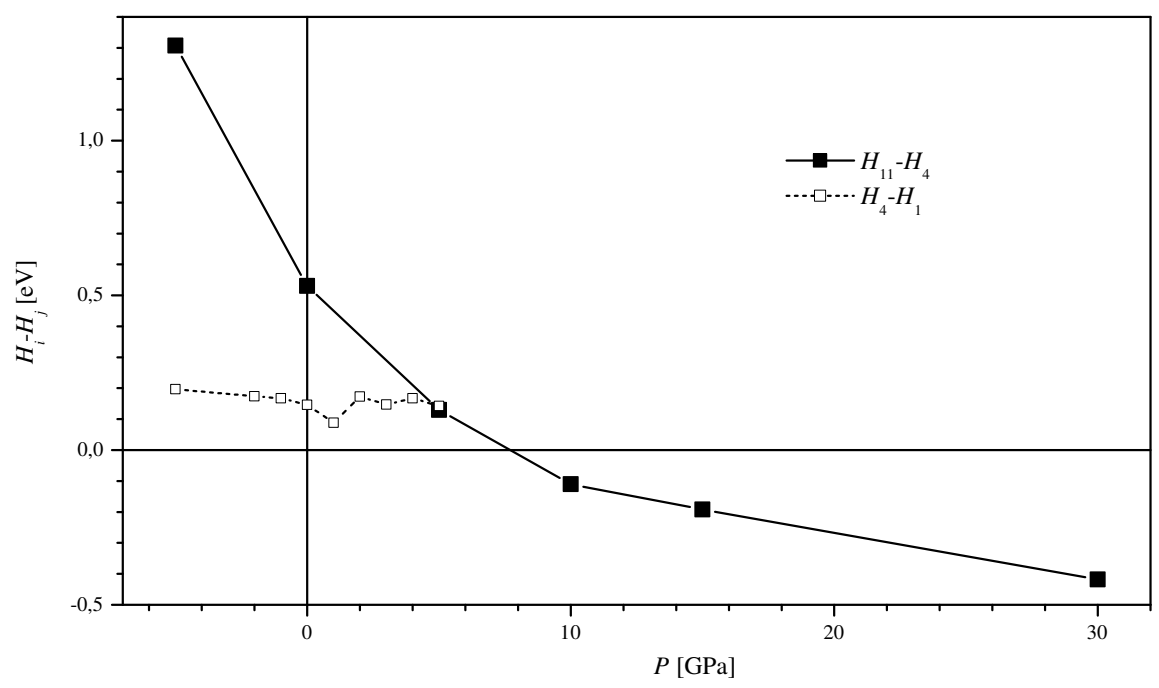

Figure 3. Dependencies of the difference of enthalpies $H_{i}-H_{j}$ on the hydrostatic pressure $P$ for the space groups $11\left(P 2_{1} / m\right), 4\left(P 2_{1}\right)$ and $1(P 1)$ of TGS crystal.

Additional calculations have shown that for the triclinic symmetry group $P 1$ of TGS crystal, the changes of the crystal unit cell angles $\alpha, \beta$, and $\gamma$ under the external pressure $P$ in the range of $-7 \ldots 7 \mathrm{GPa}$ do not exceed 0.4 percents of the initial value. This testifies to the fact that this 
hydrostatic pressure does not change the symmetry of the crystal. The enthalpy, $H=E+P V$, of the unit cell in the ferroelectric phase (space group $P 2_{1}$ ) remains greater than the corresponding value for the probable phase of triclinic symmetry (space group 1) by $0.2 \mathrm{eV}$ in the range of $-7 \ldots 7 \mathrm{GPa}$ (figure 3). This means that the probable crystal structure of the space group $P 1$ is more stable than the crystal structure of the space group $P 2_{1}$. However, one has to take into account that all the results of the present calculations of electronic structure can be generally true only for the absolute temperature $T=0 \mathrm{~K}$. If the specific heat $c_{1}$ of the crystal at the space group $P 1$ is greater than the analogous value $c_{4}$ at the space group $P 2_{1}$, then a phase transition from the space group $P 1$ to the group $P 2_{1}$ is possible at the relevant temperature $T$ depending on the difference of specific heats $\Delta c_{41}=c_{4}-c_{1}$. Positive difference of the electronic energies, $H_{4}-H_{1}=0.2 \mathrm{eV}$ (see figure 3), could be compensated at this relevant temperature $T$ by the negative difference of the thermal energies $\Delta E_{41}^{(\text {therm) }}$ caused by the negative difference of the specific heats $\Delta c_{41}$,

$$
\Delta E_{41}^{(\text {therm })}=\Delta c_{41} \cdot m_{\mathrm{c}} \cdot T
$$

where $m_{\mathrm{c}}$ is mass of the crystal unit cell. For instance, if one supposes that $\Delta c_{41}=-0.2 c_{4}\left(c_{4}=\right.$ $1530 \mathrm{~J} /(\mathrm{kg} \cdot \mathrm{K})[11])$, then for the present case $\left(\Delta E_{41}^{(\text {therm })}=-0.2 \mathrm{eV}, m_{\mathrm{c}}=1.08 \cdot 10^{-24} \mathrm{~kg}\right)$ the temperature $T$ of the probable phase transition $P 1 \leftrightarrow P 2_{1}$ is found to be equal to $T=96.8 \mathrm{~K}$. This possibility agrees well with the results of the papers $[12,13]$, where the evidence of phase transitions near the temperature of $110 \mathrm{~K}$ was found in TGS crystal.

\section{Conclusions}

The main part of the compressibility of TGS crystal is caused by the changes of interatomic distances between the quasi-molecular groups with strong chemical bonds (glycine and sulphate). The pressure induced relative changes of the interatomic distances within glycine and sulphate groups are of 5-11 times smaller than the corresponding changes of the unit cell dimensions.

Mulliken population analysis has revealed the pressure induced decrease of ionicity of the structure elements and the increase of the bond covalency of the glycine and sulphate groups. This generally leads to the pressure induced increase of the local electronic symmetry of these groups and thus can favour the pressure induced structural phase transition from the space group $P 2_{1}$ to the group $P 2_{1} / m$.

The results of the first principle study performed have demonstrated that the probable pressure induced phase transition in TGS crystal at 7 GPa can be mainly associated with the discontinuous change of the $\mathrm{C}-\mathrm{N}$ bond orientation of the glycine-1 group and the continuous change of the hydrogen atom position between glycine- 2 and glycine-3 groups.

Positive difference of the total electron energies of TGS crystal at the space groups $P 2_{1}$ and $P 1, \Delta E_{41}=E_{4}-E_{1}$, obtained in the present calculations for the external pressure $P=0$, does not exclude a corresponding temperature stimulated phase transition $P 1 \leftrightarrow P 2_{1}$ when the difference of specific heats, $\Delta c_{41}=c_{4}-c_{1}$, will appear to be negative.

\section{Acknowledgement}

The calculations presented were performed in the supercomputer centers of ICM (in Warsaw University) and WCSS (in Technical University of Wroclaw) using the Accelrys software. 


\title{
References
}

1. Fletcher S. R., Keve E. T., Skapski A. C., Ferroelectrics, 1976, 14, 775.

2. Mujica A., Rubio A., Munoz A., Needs R. J., Reviews of Modern Physics, 2003, 75, 863.

3. Nelmes R.J., McMahon M.I., Semicond. Semimetals, 1998, 54145.

4. Stankowski J., Galezewski A., Waplak S., et. al., Ferroelectrics, 1974, 6, 209.

5. Kobayashi Y., Sawada S., Furuta H., et. al., J. Phys. Condens. Matter, 2002, 1411139.

6. Choudhury R. R., Chitra R., Ramanadham M., Physica B, 2005, 366, 116.

7. Andriyevsky B., Esser N., Patryn A., et al., Physica B: Physics of Condensed Matter, 2006, 373, 328.

8. Milman V., Winkler B., White J. A., et al., Int. J. Quant. Chem., 2000, 77, 895.

9. Murnaghan F.D., Proceedings of the National Academy of Sciences, 1944, 30, 244.

10. Milman V., Winkler B., Probert M. I. J., J. Phys.: Condens. Matter., 2003, 17, 2233.

11. Landolt-Bornstein, Numerical Data and Functional Relationship in Science and Technology, New Series. Group III. V. 16 (Springer-Verlag, Berlin-Heidelberg-New-York-Tokio 1984).

12. El-Eithan F.Y., Bates A.R., Gough W., Somerford D.J., J. Phys: Condens. Matter.,1992, 4, L249.

13. Sheen C.K., Chow T.C., Hu M.L., et. al., Chin. J. Phys., 1997, 35, 929.

\section{Вплив гідростатичного тиску на структурні і електронні параметри кристалів ТГС (розрахунки з перших принципів)}

\author{
Б.Андрієвський, В.Цєплюх-Троянек, А.Патрин \\ Факультет електроніки та інфоматики, Кошалінський Технологічний Університет, \\ вул. Снядецьких 2, PL-75-453, Кошалін, Польща \\ Отримано 4 вересня 2006 р.
}

\begin{abstract}
Проведені розрахунки з перших принципів впливу гідростатичного тиску на структурні і електронні параметри кристалів ТГС. Розрахунки виконані в межах теорії функціоналу густини з використанням програми CASTEP. Об'ємна залежність повної електронної енергії $E(V)$ елементарної комірки кристалу описується ізотермічним рівнянням стану Бірча-Мурнагана третього порядку. Об'ємний модуль стиску кристалу, визначений в області тисків $-5 \ldots 5$ ГПа, становить $K=45 \pm 5$ ГПа. Виявлено, що відносні баричні зміни параметрів елементарної комірки кристалу є лінійними в області $-5 \ldots 5$ ГПа. Перетин кривих баричних залежностей ентальпії, що відповідають сегнетоелектричній і несегнетоелектричній фазам, при тиску $P=7.7$ ГПа свідчить про можливий стимульований тиском фазовий перехід у кристалі ТГС.
\end{abstract}

Ключові слова: сегнетоелектрики, структурні і електронні параметри, гідростатичний тиск

PACS: $71.15 . \mathrm{Nc}, 77.80 . \mathrm{Bh}, 77.84 . \mathrm{Fa}$ 